\title{
A gridded dataset of hourly precipitation in Germany: Its construction, climatology and application
}

\author{
Marcus Paulat ${ }^{1,4 *}$, Christoph Frei ${ }^{2}$, Martin Hagen ${ }^{3}$ and Heini Wernli $^{1}$ \\ ${ }^{1}$ Institute for Atmospheric Physics, University of Mainz, Germany \\ ${ }^{2}$ Federal Office of Meteorology and Climatology Meteo Swiss, Zürich, Switzerland \\ ${ }^{3}$ Institut für Physik der Atmosphäre, Deutsches Zentrum für Luft- und Raumfahrt, Oberpfaffenhofen, Germany \\ ${ }^{4}$ Current affiliation: Deutscher Wetterdienst, Offenbach, Germany
}

(Manuscript received March 3, 2008; in revised form September 16, 2008; accepted September 16, 2008)

\begin{abstract}
A so-called disaggregation technique is used to combine daily rain gauge measurements and hourly radar composites in order to produce a dataset of hourly precipitation in Germany on a grid with a horizontal resolution of $7 \mathrm{~km}$ for the years 2001-2004. This state-of-the-art observation-based dataset of precipitation has a high temporal and spatial resolution and will be extended continuously during the upcoming years. Limitations of its quality, which are due to intrinsic problems with observing the highly variable field of precipitation, are discussed and quantified where possible. The dataset offers novel possibilities to investigate the climatology of precipitation and to verify precipitation forecasts from numerical weather prediction models. The frequency of hourly precipitation in Germany above the detection limit of $0.1 \mathrm{~mm} / \mathrm{h}$ amounts to $10-30 \%$ in winter, with clear maxima in the mountainous regions, and to 6-20\% in summer, when the spatial variability is considerably reduced. The 95th percentile of the frequency distribution is significantly larger in summer than in winter, with local maxima in the mountainous regions in winter, and in the Alpine Foreland and upper Elbe catchment in summer. It is shown that the operational model COSMO-7 with a horizontal resolution of $7 \mathrm{~km}$ captures the geographical distribution of the frequency and of the 95th percentile of hourly precipitation in Germany very well. In contrast, the model is not able to realistically simulate the diurnal cycle of precipitation in any region of Germany during summer.
\end{abstract}

\section{Zusammenfassung}

Mit Hilfe einer sogenannten Disaggregierung werden tägliche Niederschlagsmessungen und stündliche Radarkomposits kombiniert, um einen stündlichen Niederschlagsdatensatz in Deutschland für die Jahre 2001-2004 auf einem Gitter mit einer horizontalen Auflösung von 7 km zu erstellen. Dieser Datensatz hat eine hohe zeitliche und räumliche Auflösung und wird in den nächsten Jahren fortlaufend ergänzt. Die Qualität des Datensatzes, die von den intrinsischen Problemen bei der Messung des stark variablen Niederschlagsfeldes betroffen ist, wird diskutiert und wo möglich quantifiziert. Der Datensatz bietet neue Möglichkeiten zur Untersuchung klimatologischer Aspekte des Niederschlags und zur Verifikation von Niederschlagsvorhersagen von numerischen Modellen. Die Häufigkeit stündlicher Niederschläge oberhalb der Messgrenze von $0,1 \mathrm{~mm} / \mathrm{h}$ beläuft sich in Deutschland auf $10-30 \%$ im Winter (mit klaren Maxima in den Mittelgebirgsregionen und im Alpenvorland) und auf 6-20\% im Sommer (mit einer deutlich reduzierten räumlichen Variabilität). Das 95-ste Perzentil der Verteilung des stündlichen Niederschlags ist im Sommer deutlich grösser als im Winter. Im Winter zeigen sich lokale Maxima des 95-sten Perzentils in den Gebirgsregionen und im Sommer im Alpenvorland und oberen Einzugsgebiet der Elbe. Das operationelle Modell COSMO-7 mit einer horizontalen Auflösung von $7 \mathrm{~km}$ erfasst die geographische Variabilität der stündlichen Niederschlagshäufigkeit und des 95-sten Perzentils der Verteilung gut. Im Gegensatz dazu ist das Modell in keiner Region Deutschlands in der Lage, den Tagesgang des Niederschlags im Sommer realistisch zu simulieren.

\section{Introduction}

Precipitation is one of the key meteorological variables, essential for everyday weather forecasting, and for applications for instance in the fields of hydrology and agrometeorology. Because of the multitude of physical processes involved in the formation of precipitation, ranging from the large-scale forcing of vertical motions to complex microphysical processes in different cloud types, it is particularly difficult to accurately predict

${ }^{*}$ Corresponding author: Marcus Paulat, Deutscher Wetterdienst, Frankfurter Strasse 135, 63067 Offenbach, Germany, e-mail: marcus.paulat@dwd.de the spatial distribution and the amplitude (and during the cold season sometimes also the phase) of precipitation. In addition, compared to other meteorological fields, precipitation is frequently characterized by smallscale structures, associated for instance with the formation of isolated deep convective systems or with precipitation enhancement due to the underlying topography. Limitations in our understanding of the processes involved in the formation of precipitation, their representation in models and uncertainties in the initial state of a model forecast render quantitative precipitation forecasting (QPF) a very challenging and not yet satisfactorily resolved task of weather prediction (e.g., EBERT et 
al., 2003; FRITSCH and CARBOne, 2004). An important contribution for improving model predictions is the development of more sophisticated verification strategies for QPFs. Several alternative techniques have been developed during the recent years, in order to assess the quality of QPFs in a meaningful way (see Ross A et al., in preparation, for a comprehensive review).

During the last years, an important development in numerical weather prediction has been the advent of veryhigh resolution and even convection resolving limitedarea models, like for instance in Germany the COSMODE model with a horizontal resolution of $2.8 \mathrm{~km}$, which is operational since April 2007. The verification of such models becomes particularly challenging, on the one hand because of the high spatial resolution, and on the other hand because of the need to verify these models on short time scales of typically one hour. Also, for variables like precipitation, which are characterized by large small-scale variability, it is desirable to perform an observations-to-model verification approach, which calls for the availability of an observational dataset on the model grid. Current networks of rain gauge stations with hourly time resolution are not dense enough for producing a gridded analysis with a spatial resolution comparable to the numerical model. It is for this reason that in this study a so-called disaggregation technique will be used, which suitably combines information from the much denser network of daily measuring rain gauge stations and radar. This technique has been developed during the Mesoscale Alpine Programme (HAGEN et al., 2003) for the Alpine region and has been applied for producing a 15-year dataset of hourly precipitation in Switzerland (WüEST et al., submitted). Such a dataset offers novel possibilities for the verification of high-resolution QPFs on short (hourly) time scales. In addition, it provides the basis for important climatological analyses, for instance of the frequency distribution of precipitation and its diurnal cycle (TRENBERTH, 1999).

In the literature, several methods have been proposed for deriving precipitation analyses by combination of rain gauge and radar measurements. One class of techniques utilizes rain gauge observations for the calibration/adjustment of radar-based rainfall estimates. GJERTSEN et al. (2004) give an overview of the variety of techniques used by European weather services. These approaches are primarily designed to rectify known technical difficulties of radar rainfall estimation, such as the variation of $Z-R$ relationships or the limited visibility in mountainous terrain (see also GEKAT et al., 2003; Germann et al., 2006). Another class of techniques uses more formal blending procedures where the relative advantages of the two observation platforms are exploited, i.e. high accuracy at single points on the one hand (rain gauges), and fine resolution and spatial coverage on the other hand (radar). Concepts of geostatistics and Bayesian statistics have mostly been employed for this purpose (e.g., SEO et al., 1990; SEO, 1998; TODINI,
2001; HABERLANDT, 2007; DeGaetano and Wilks, 2008). These two classes of techniques are primarily designed for real-time rainfall estimation. Since rain gauge information is very coarse due to the restricted number of stations monitoring at sub-daily time-scales, the fine spatial resolution is the key added value from radar measurements. In contrast, the disaggregation method applied in this paper can not be used in real time, since it requires quality-checked rain gauge data from dense climatological networks with daily time resolution. This data source provides spatial information close to the effective resolution of current operational weather forecasting models and hence the key added value from radar is high time resolution. The disaggregation method is designed to exploit this temporal information while maintaining maximum consistency with the daily measurements from the climatological rain gauge networks.

The next section provides information about the datasets used in this study. In section 3, the disaggregation technique is explained and the resulting hourly precipitation dataset is compared with hourly station measurements. Climatological applications of the dataset related to the frequency distribution of precipitation and the summertime diurnal cycle are presented in section 4 . In section 5, the observed characteristics are compared with those derived from mesoscale numerical model forecasts, revealing some important deficiencies of the model. The main conclusions of the study are summarized in section 6 .

\section{The datasets}

In this section, an overview is given of the datasets used in this study: rain gauge observations, the German radar composite, and precipitation forecasts from the Swiss operational mesoscale numerical model COSMO-7. All three datasets were available for the time period from January 2001 to December 2004. Also, the methods are presented that have been used to bring the different datasets onto the same regular grid.

\subsection{Rain gauges}

In Germany, 24-hour accumulated precipitation measurements are available from about 3500 rain gauge stations, operated by the German Weather Service (DWD). Although the number of these stations has decreased over the years (3964 stations in 2001, 3303 in 2004), they provide a dense network of quasi-continuous measurements with a fairly homogeneous coverage over the entire country (see Fig. 2.3 in PAULAT, 2007) and an average distance between neighboring stations of $10 \mathrm{~km}$. However, the density of the stations is reduced at higher elevations, since measurement stations are preferentially located in valleys. In Germany, this is particularly relevant in the northern Alpine foreland along the southern border to Austria. In the presence of height dependence 
in the precipitation distribution, such biases in the station distribution can lead to systematic errors in the gridding procedure (EKHART, 1948; PECK and BROWN, 1962). In order to avoid such biases, a climatological precipitation dataset from the DWD is used during the gridding process (see section 2.2 for details). By convention, the daily totals are manually or automatically recorded at 0730 local time, which corresponds to 0630 UTC during winter and 0530 UTC during summer. Most gauges are of the type Hellmann with a collection area of $200 \mathrm{~cm}^{2}$.

DWD performs its operational quality control to the gauge measurements. Here we also apply a spatial consistency check using a refined version of the procedures of BEHRENDT (1992). While these checks are able to eliminate gross random errors, it is important to keep in mind that they cannot account for the systematic errors in the measurements of rain gauges. These errors can be substantial and have different sources (e.g., NEFF, 1977; RICHTER, 1995; YANG et al., 1999). The main error source is wind-induced undercatch, which is particularly prominent in winter and at high altitudes (strong winds, large fraction of snowfall). Another contribution is from evaporation losses (mainly during the warm season). According to RICHTER (1995), 5.2 \% of precipitation in Germany occurs as snow and $13.2 \%$ as a mixture of rain and snow. For Germany, errors due to windrelated undercatch are estimated to $12.3 \pm 3.1 \%$ on average during winter, and to $5.6 \pm 1.7 \%$ during summer. In the long-term average, the total error has been estimated as $16.7 \%$. Despite these biases, rain gauge measurements can be regarded as those with the best absolute accuracy operationally available. For analyses that extend over long (multi-decadal) time periods, they constitute the only reliable data source.

\subsection{Gridding of the rain gauge measurments}

Comparison of observed and simulated precipitation is most meaningful, if the observations that typically correspond to point measurements are suitably upscaled to the model grid. The main reason for this observationsto-model transformation is that grid point values from the model correspond to the area means. In this study, the gridding technique used by FREI and SCHÄR (1998) has been implemented. The grid has been chosen identical to the COSMO-7 model grid with a horizontal resolution of $7 \mathrm{~km}$ (see section 2.4). The technique is based upon the SYMAP interpolation algorithm by SHEPARD (1984), which is an angular distance-weighting scheme frequently adopted in precipitation analysis (see e.g., RUDOLF et al., 1992). For every grid point, a weighted average is calculated for all stations within a search radius. The radius is chosen in such a way that at least three stations contribute to the averaging. Figure 1a shows the geographical distribution of the search radius $\mathrm{i}$, expressed in units of the mesh size $\Delta x=7 \mathrm{~km}$. In almost all regions $i$ is equal to 2 , which means that gridded values are influenced by station values within a distance of $14 \mathrm{~km}$. Since the weighting function is small for distances larger than $\Delta x$, the effective resolution of the gridded dataset is in the range of $14-28 \mathrm{~km}$. This effective resolution is coarser than the model grid ( 7 $\mathrm{km}$ ), however it corresponds well to the meaningfully resolved model structures that are larger than $2 \Delta x$. In addition, Fig. $1 \mathrm{~b}$ displays the number of stations that contribute to the averaging at every model grid point. This value is typically 3 or 4 , and reaches up to more than 10 in regions where the gauge network is particularly dense, which interestingly is the case in the more mountainous regions of Germany (e.g., the Alpine Foreland, southern Black Forest, Harz, Thüringer Wald).

In order to address the issue of poor representativity of the gauge network in mountainous terrain, the gridding procedure made use of a high-resolution precipitation climatology. To this end the climatology of the DWD was utilized, which reproduces long-term mean monthly conditions for the years 1961-1990 (MÜLLERWeSTERMEIER, 1995). Adopting a regional detrended kriging approach, the climatology considered height gradients explicitly on a grid resolution of $1 \mathrm{~km}$ in the horizontal. Our application of the SYMAP technique operates on fractional anomalies of the daily station totals relative to the co-located mean monthly value in the climatology. The final precipitation grids are then obtained by multiplying the gridded anomalies with the climatology. This technique has been introduced by WIDMANN and BRETHERTON (2000) and NEW et al. (2000). Compared to the gridding of daily totals directly, this procedure tends to increase area-mean precipitation values in the Alpine region of Southern Germany by typically $5-15 \%$ but has no major effect elsewhere (FREI et al., 2003).

It is important to note that the gridded precipitation data exhibit lower intensities and higher wet-day frequencies compared to station values (FREI et al., 2003). This is a direct consequence of the upscaling procedure. It underlines the need for gridding in the evaluation of numerical models (see also OSBORN and HulME, 1997). Note that the gridded precipitation data can only be regarded as a best estimate of the grid cellaveraged real precipitation field. Using a specific Monte Carlo approach, FREI et al. (in print) estimated the uncertainties of gridded precipitation data and found that they are large for point values but decrease rapidly toward scales comparable to the effective resolution of the dataset $(2 \Delta x)$. At these scales, uncertainties are typically smaller than $10 \%$.

\subsection{The radar composite}

Hourly composites from the 16 operational precipitation radars over Germany are computed from 15minute composites with $4 \mathrm{~km}$ horizontal resolution, the so-called PC product of the German Weather Service 

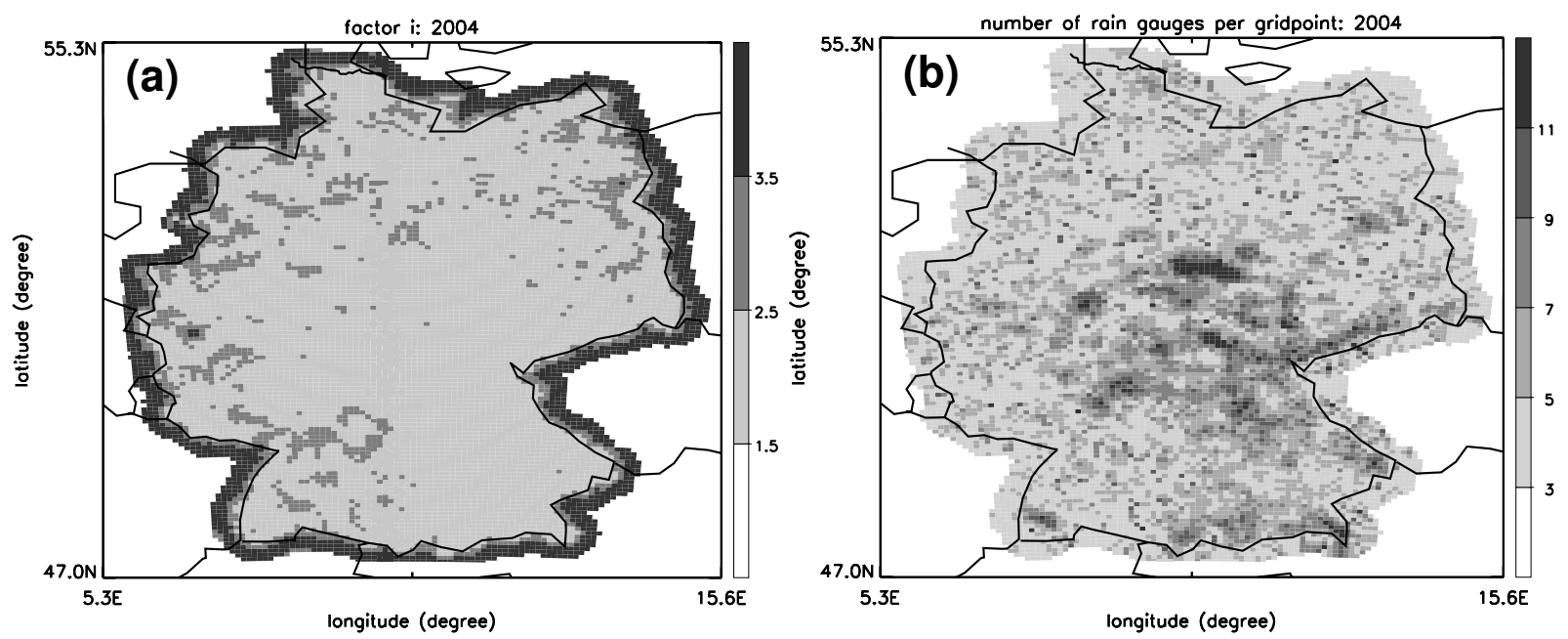

Figure 1: Geographical distribution of (a) the search radius, used for the upscaling, expressed in units of the mesh size $(\Delta x=7 \mathrm{~km})$; (b) the number of rain gauge stations that contribute to the averaging at every grid point. (These results are based upon the gridding of the rain gauges for the year 2004 only.)

(DWD). In regions where the individual radars overlap, the higher reflectivity value is taken for the composite. Except for small regions in the SE, NE and north of Germany, the 16 radars cover the entire country. Unfortunately, on 97 days during the four years 2001-2004 no radar data was available (6.6\% missing data).

The radar composite data are originally given in six reflectivity classes, in units of dBZ. The following relationship between radar reflectivity $Z$ (in $\mathrm{mm}^{6} / \mathrm{m}^{3}$ ) and precipitation $R$ (in $\mathrm{mm} / \mathrm{h}$ ) is used by DWD

$$
Z=256 R^{1.42}
$$

It is important to note that various empirical $Z-R$ relationships exist in the literature (e.g., BATTAN, 1973), reflecting the variability and current lack of understanding associated with the microphysical processes leading to the formation of precipitation. Unfortunately, no raw data have been available for the composite; instead the radar composite yields reflectivity values only in a few reflectivity classes (see Table 1). According to the $Z$ $R$ relationship (eq. 2.1), the range of reflectivity values for every category corresponds to a range of precipitation values. For our quantitative investigations, a representative value had to be determined for every category (see third column in Table 1). Note that this choice of representative values is subjective and leads to additional uncertainty of the quantitative precipitation values associated with radar reflectivities. Whereas intermediate values have been chosen for the lower intensity categories, representative values have been selected toward the lower end of the range for higher intensity categories, because of the strong decrease of precipitation frequencies towards higher intensities. The last column in Table 1 gives the 15-minute precipitation values corresponding to the reflectivity categories. They are the basis for calculating the hourly precipitation values from the radar composite. Finally, the hourly radar precipitation values have been brought from the original $4 \times 4 \mathrm{~km}$ grid to the $7 \times 7 \mathrm{~km}$ grid of the numerical model (see next section) by averaging over the 1-4 radar grid points within the model grid box.

\subsection{COSMO model forecasts}

The COSMO model is a non-hydrostatic grid point model based on the fully compressible dynamic equations, developed by the Consortium for Small-scale Modelling (COSMO) and used for operational weather prediction in several European countries; see STEPPELER et al. (2003) for a detailed model description. During the years 2001-2004 it was operated both by the German and Swiss weather services with a horizontal resolution of $7 \mathrm{~km}$. For reasons of data availability, we used precipitation forecasts from the Swiss operational COSMO model, the so-called COSMO-7 (formerly referred to as "Alpine Model", aLMo) for our analyses. The model domain covers the region of western and central Europe (see PAUlat, 2007, Fig. 2.1). Each day, two 72-hour forecasts were started at 00 UTC and 12 UTC, respectively. From the operational runs, accumulated precipitation forecasts were available every hour. In this study, we show results from the 00 UTC runs, for hourly QPFs between forecast step 6 and 30 hours. Results from the 12 UTC forecasts are very similar (PAULAT, 2007). With a resolution of $7 \mathrm{~km}$, the model captures the main topographic features in Germany fairly accurately. As initial and boundary conditions, forecasts from the global models GME (until 15 September 2003) and ECMWF (since 16 September 2003) have been used. Two important changes have been made to COSMO-7 during the time period considered in this study: since 31 October 2001, a nudging data assimilation technique has been used; and on 16 November 
Table 1: The six reflectivity categories of the PC product by DWD and the category without a reflectivity signal. From left to right: reflectivity range for every category; associated precipitation range (according to eq. 2.1); estimated category mean precipitation value; and corresponding 15-min precipitation value.

\begin{tabular}{cccc}
\hline Reflectivity [dBZ] & Precipitation $[\mathrm{mm} / \mathrm{h}]$ & $\begin{array}{c}\text { Category mean } \\
\text { precipitation }[\mathrm{mm} / \mathrm{h}]\end{array}$ & $\begin{array}{c}\text { Corresponding } \\
\text { 15-min precipitation } \\
\text { value [mm] }\end{array}$ \\
\hline $0-7$ & $0-0.1$ & 0 & 0 \\
$7-19$ & $0.1-0.5$ & 0.4 & 0.1 \\
$19-28$ & $0.5-1.9$ & 1.2 & 0.3 \\
$28-37$ & $1.9-8.1$ & 3.6 & 0.9 \\
$37-46$ & $8.1-34$ & 10 & 2.5 \\
$46-55$ & $34-149$ & 56 & 14 \\
$>55$ & $>149$ & 160 & 40 \\
\hline
\end{tabular}

2004, the grid-scale precipitation scheme was changed from a diagnostic to a prognostic treatment.

\section{The disaggregation technique}

\subsection{The technique}

Here we apply a temporal disaggregation technique of 24-hour accumulated rain-gauge analyses with radar data to produce hourly precipitation fields. HAGEN et al. (2003) performed a first feasibility study of the technique within the Mesoscale Alpine Programme for the region of the European Alps. Later, the technique was fully developed and applied for an extended time period from 1992 till 2006 in Switzerland by WÜEST et al. (submitted). The rationale of the technique is to combine the advantages of the rain gauge observations (dense observation network, relatively high accuracy) with those of the radar composite (high spatial and temporal resolution) - as already outlined in section 1 . As a prerequisite for the application of the method, daily accumulated rain gauge analyses and hourly radar composites have to be available on the same grid (cf. sections 2.2 and 2.3).

Mathematically, the disaggregation technique is straightforward. For every grid point $(i, j)$ the hourly-disaggregated precipitation value is calculated as

$$
R_{d i s, h}(i, j)=R_{\text {rad }, h}(i, j)^{*} R_{o b s, d}(i, j) / R_{r a d, d}(i, j),
$$

where $R_{r a d, d}$ and $R_{r a d, h}$ denote the daily and hourly radar precipitation estimate, respectively, and $R_{o b s, d}$ the value from the gridded rain gauge analysis. Equation (3.1) can be interpreted in two ways: (i) the hourlydisaggregated value corresponds to the hourly radar estimate, corrected by the ratio of the daily totals from rain gauges and radar; (ii) the hourly-disaggregated value corresponds to a fraction of the daily total rain gauge value that is given by the contribution of the considered hour to the daily total radar estimate. Note that the radar determines the temporal variability during the day, whereas the daily-accumulated value of the disaggregated dataset corresponds exactly to the rain gauge analysis. For instance a systematic overestimation of precipitation by radar does not affect the quality of the disaggregation. Figure 2 shows an example, for the hour from 0530 to 0630 UTC on August 12, 2002, i.e. during the precipitation event that led to the severe Elbe flooding. Comparison of the hourly radar estimate (Fig. 2c) with the disaggregated field (Fig. 2d) shows that for this particular hour, the latter has larger values in the Erzgebirge and lower values in the western part of Germany, in agreement with the ratio of the daily totals (Figs. 2a,b).

It is important to note that the disaggregation procedure incorporates information from the radar measurements solely for the purpose of enhancing the temporal resolution in the analyses of classical rain-gauge measurements. Unlike other, more complex combinations of rain-gauge and radar measurements (such as those described in SEO, 1998 and HABERLANDT, 2007), the disaggregation does not make use of the higher spatial information provided by radar observations. The aim of the present methodology is to retain the high accuracy of rain gauge measurements, to keep consistency with daily analyses from rain gauges alone and to avoid effects from radar biases. Clearly, model evaluations at an even finer scale would ultimately require more sophisticated techniques where the combination of data sources can exploit the wealth of information in radar composites that is discarded in the present disaggregation. The fact that the effective resolution of the daily rain-gauge analysis is approximately equal to the effective model resolution did not make higher spatial resolution an ultimate target of the present study. But we recognize that even better precipitation analyses could be derived with sophisticated techniques that make more complete use of the available data.

\subsection{Potential problems}

Due to inconsistencies between rain gauge and radar data, there are three main problems that can occur when applying the disaggregation technique: (i) the radar does not observe any precipitation where the rain gauge analysis indicates precipitation values greater than zero, 

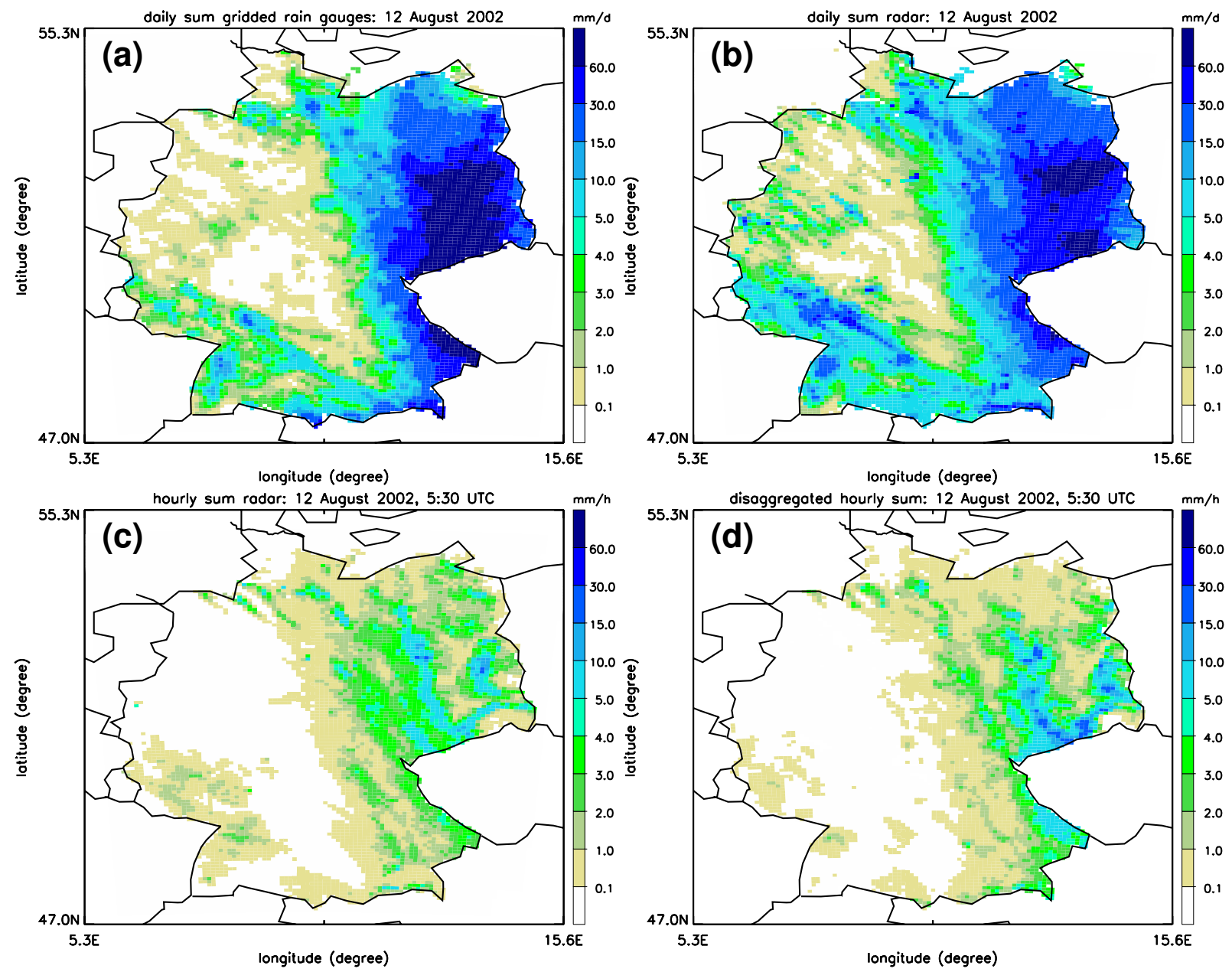

Figure 2: Example for the disaggregation technique. Precipitation fields over Germany on 12 August 2002 on the grid of COSMO-7. (a) 24-h accumulated precipitation analysis from rain gauges, (b) 24-h accumulated radar composite, (c) 1-h accumulated radar composite for the hour from 0530 to $0630 \mathrm{UTC}$, and (d) the resulting disaggregated precipitation field for the hour from 0530 to 0630 UTC.
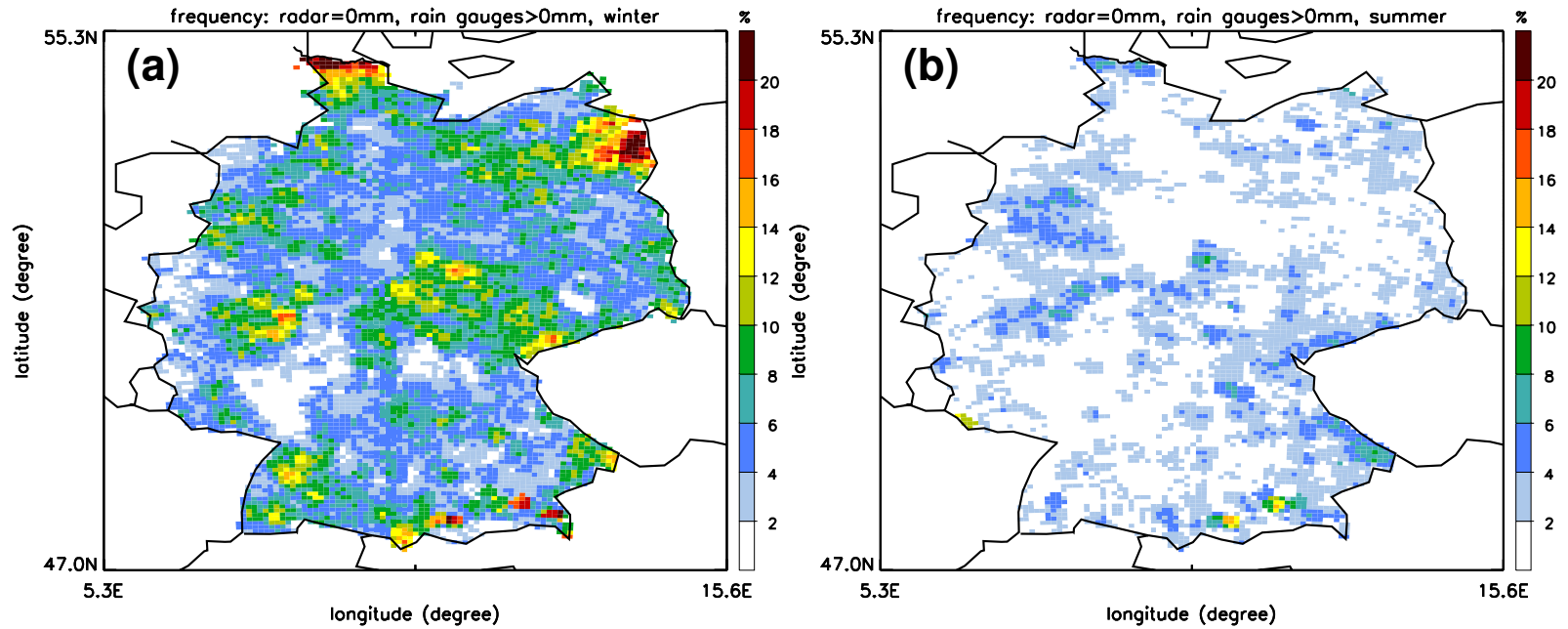

Figure 3: Frequency (in \%) of the problem of the first kind, during the years 2001-2004, for (a) winter and (b) summer, when 24-h accumulated precipitation values from radar are zero, and values from the gridded rain gauge analysis are larger than zero. 

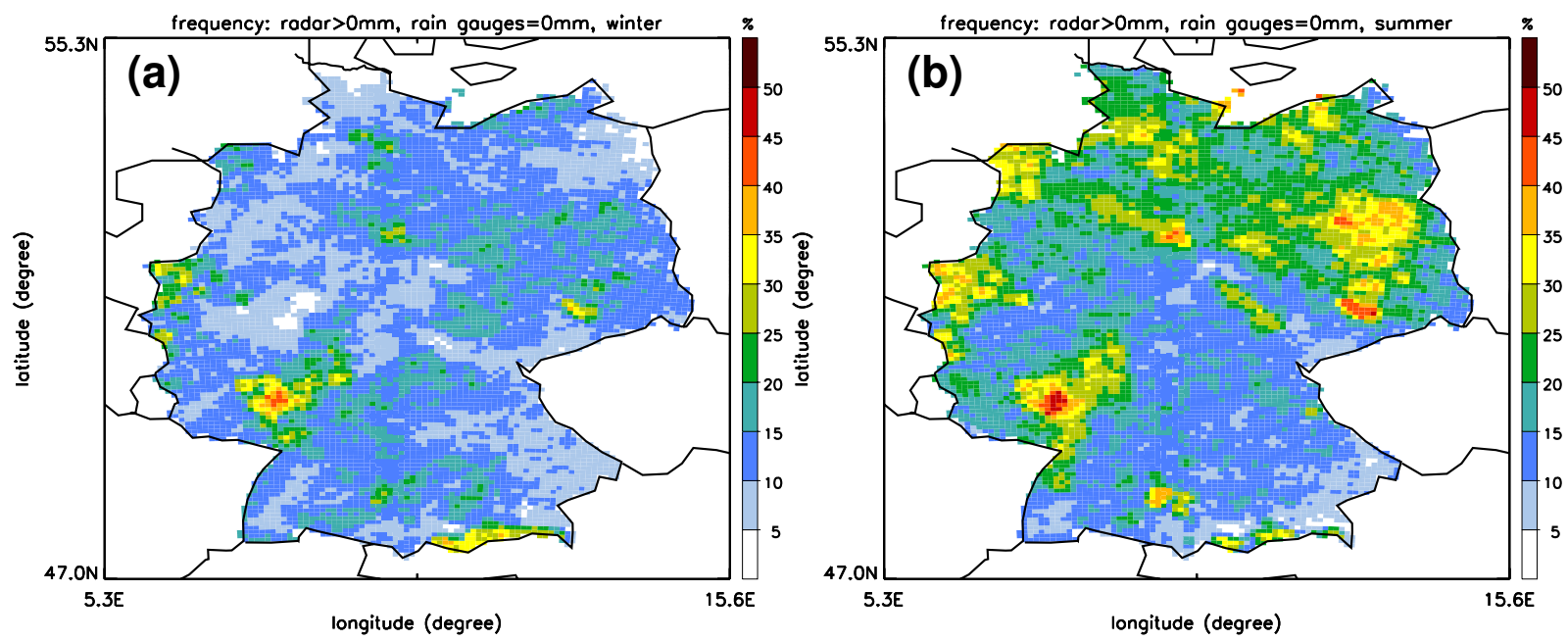

Figure 4: Frequency (in \%) of the problem of the second kind, during the years 2001-2004, for (a) winter and (b) summer, when 24-h accumulated precipitation values from the gridded rain gauge analysis are zero, and values from radar are larger than zero.

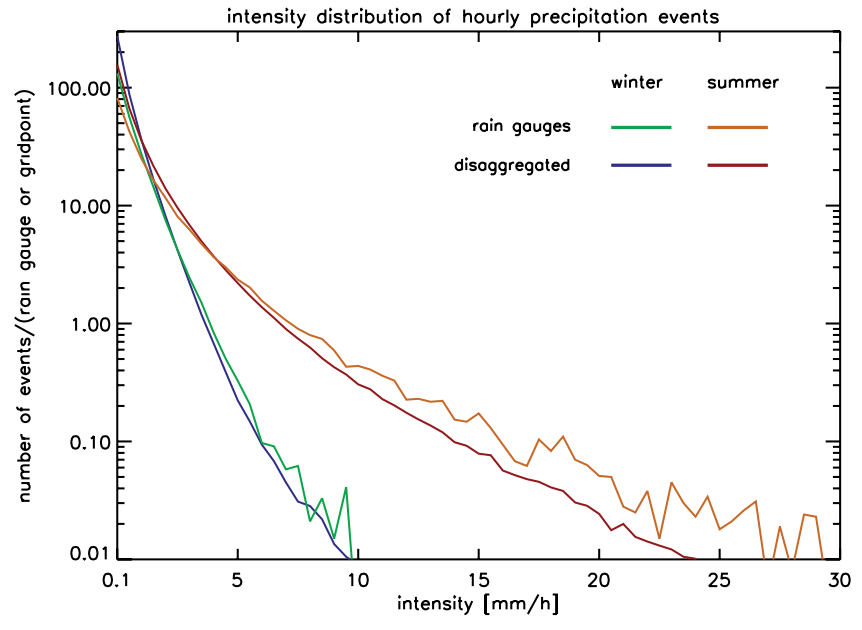

Figure 5: Frequency distribution of hourly preciptiation values from station measurements (green and orange lines for winter and summer, respectively) and the disaggregated dataset (blue and red lines for winter and summer, respectively) during the years 2001-2004. The bin-width is $0.5 \mathrm{~mm} / \mathrm{h}$, except for the first bin, which extends from 0.1 to $0.5 \mathrm{~mm} / \mathrm{h}$. The distributions are normalized with the number of stations and grid points, respectively, and the values denote the number of events in a particular bin per station or grid point.

(ii) the rain gauge analysis indicates no precipitation but the radar estimate is greater than zero, and (iii) both measurements are non-zero, and real and spurious signals contribute to the radar reflectivities. The problem of the first kind can occur due to failures of radar operation, radar shadowing in complex terrain, fog (which can lead to precipitation at the surface but can not be detected by radar), and/or due to an effect of smoothening associated with the gridding technique. The problem of the second kind can also occur due to different reasons, for instance in case of spurious radar echoes from the ground, problems with the $Z-R$ relationship in case of high reflectivities associated with the melting layer, if precipitation observed by radar does not reach the ground, and/or if the spatial resolution of the rain gauge network is too coarse to capture the event. Finally, problems of the third kind most likely occur near radar stations, where ground echoes and signals from precipitation (e.g., showers) might occur alternatingly during the day.

For the years 2001-2004, problems of the first kind occur with a frequency of $8 \%$ (in $4 \%$ due to missing radar data, and in $4 \%$ due to radar shadowing and smoothening introduced by gridding). In these situations, disaggregation is not possible and the hourlydisaggregated values are set to missing data for the entire day. During the four years considered, disaggregation has been possible on $92 \%$ of the days. Figure 3 shows the geographical distribution of the frequency of this type of problem for winter and summer. Frequencies are clearly larger during winter (and autumn, not shown) when maxima occur in certain regions of the German boundaries where radar coverage is insufficient (e.g., in Schleswig-Holstein and in the NE part of Germany) and near topographical obstacles. During summer (and spring, not shown), when precipitating clouds typically extend to higher altitudes and fog is not an issue, this type of problem occurs rarely.

The problem of the second kind is more frequent, it occurs in $15 \%$ of the cases. Figure 4 reveals that it occurs mainly in preferred regions close to the radar locations (mainly ground echoes), in particular near the older radar systems (located at Frankfurt, Essen and Munich). Frequencies are slightly higher during summer, which might also indicate problems of the rain gauge network not capturing small-scale and short-lived convective events. The reason for the enhanced frequencies in the SW of Germany is unclear, although the problematic quality of the Frankfurt radar (which has been 
replaced in July 2007) seems to be a reasonable explanation. Since absolute precipitation values in the hourly analysis rely in the first place on rain gauge observations, all hourly-disaggregated values are set to zero if a problem of the second kind occurs.

Problems of the third kind can occur in situations where both datasets indicate that precipitation has reached the ground, but the daily total radar signal is contaminated by contributions for instance from ground echoes. It is very likely that these situations occur, in particular near the radar locations, but they cannot be automatically identified and excluded from the disaggregation procedure. Therefore, they can erroneously lead to the repartitioning of an actually short-lived precipitation event over a much longer period, possibly over an entire day. The disaggregated dataset then contains the actual precipitation event with reduced amplitude and a spurious "noise" extending over several hours associated with ground echoes. However, given the generally reasonably good quality of the radar composite and the low intensity of ground echoes, this problem rarely affects the disaggregated dataset in a severe way.

\subsection{Comparison with hourly rain gauge measurements}

As a test of the quality of the disaggregated dataset, its frequency distribution is compared to the one obtained from independent station measurements with hourly time resolution. However, note that such a comparison can only yield qualitative information, since the disaggregated dataset represents spatial averages over areas of about $15 \times 15 \mathrm{~km}$, and its statistics are therefore not strictly comparable to point measurements. Figure 5 shows these frequency distributions for the winter and summer seasons, respectively. For every grid point of the disaggregated dataset, and for every station with hourly measurements, the frequency of precipitation intensities has been determined in bins with a width of $0.5 \mathrm{~mm} / \mathrm{h}$ (with the exception of the first bin ranging from 0.1 to $0.5 \mathrm{~mm} / \mathrm{h}$ ). The distributions in Fig. 5 correspond to the averages over all grid points and stations, respectively. There is very good agreement between the two datasets in both seasons. The deviations (overestimation of weak intensities and underestimation of very high intensities by the disaggregated dataset) can be expected as a result of the different areal supports (point vs. area mean values). Note also, not surprisingly, the much larger frequencies of intense precipitation during the summer season compared to winter.

As a second, more specific comparison, two representative example time series of hourly precipitation values are shown in Fig. 6 from rain gauge observations at a selected station in central Germany (Bad Kissingen, $282 \mathrm{~m}$ a.s.l.) and from the disaggregated dataset at the nearest grid point. During both time periods there are single days with missing data values in the disaggregation dataset (see section 3.2), as indicated by black horizontal bars. For the remaining days, the two time series show a good qualitative agreement. The quantitative differences (the peak values are typically smaller in the disaggregated dataset, in particular during summer) are as expected given the different areal support of the two datasets and the differing characteristics of winter- and summer-time precipitation.

These brief comparisons with hourly rain gauge measurements, which provide a fully independent dataset, support the accuracy and usefulness of the disaggregated dataset in Germany. Aspects of its climatology and applications for QPF validation are presented in the next sections.

\section{Climatological analyses of hourly precipitation in Germany}

\subsection{Hourly precipitation frequencies}

As a first climatological analysis of the dataset, the geographical distribution of the frequency of hourly precipitation above a threshold of $0.1 \mathrm{~mm} / \mathrm{h}$ is shown for the winter and summer seasons in Fig. 7. This threshold has been chosen since it corresponds to the detection limit of precipitation with rain gauge measurements. Therefore, Fig. 7 provides information about the frequency (in percent) of hours with rain and without rain. Frequencies are generally higher and geographically more variable in winter compared to summer. During winter (Fig. 7a), maximum values are about $30 \%$ in the Alpine Foreland, and other local maxima above $20 \%$ are associated with mountain regions (e.g., the Black Forest, Swabian Alb, Harz and the Thüringer Wald). Minimum values below $9 \%$ occur in the very NE of Germany (Usedom) and low precipitation frequencies $(<10 \%)$ extend over most of eastern Germany and the Rhine-Main area. During summer (Fig. 7b), maximum frequency amounts to only $22 \%$ and occurs again in the Alpine Foreland. Lowest values $(<8 \%)$ prevail in large parts of eastern Germany and in a band extending from the Saarland to the Thüringer Wald. During spring (not shown), the precipitation frequency distribution is very similar to summer (with slightly enhanced values in the mountainous regions), and during autumn the pattern resembles to the one for winter, however with reduced maximum amplitudes (see Fig. 5.3 in PaUlat, 2007).

\subsection{Intense events}

Figure 8 shows the geographical distribution of the 95th percentile of the frequency distribution of hourly precipitation during the winter and summer season. As for the frequency of hours with precipitation, there is a striking difference between the two seasons, now with much larger values during summer (maxima of $8 \mathrm{~mm} / \mathrm{h}$ compared to $5.5 \mathrm{~mm} / \mathrm{h}$ during winter). However, spatial variability is again more pronounced during winter. In winter (Fig. 8a), the largest values occur in the mountainous 

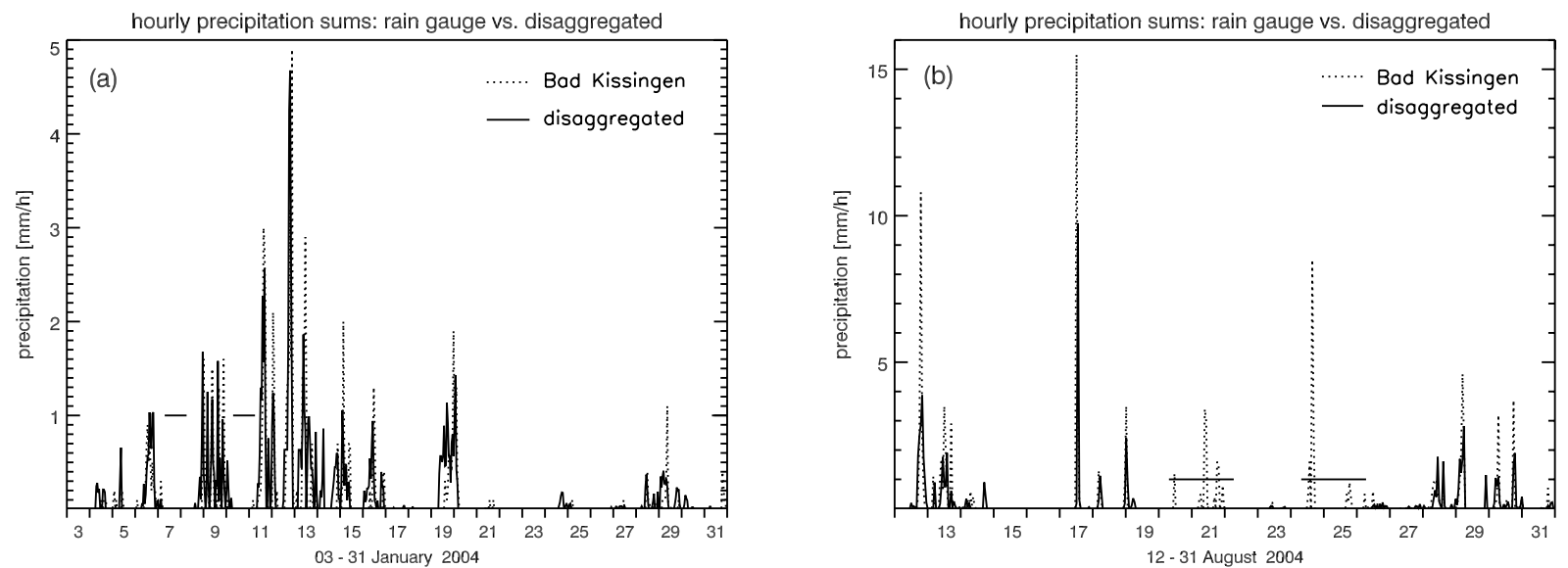

Figure 6: Time series of hourly precipitation (in $\mathrm{mm} / \mathrm{h}$ ) at Bad Kissingen $\left(10.08^{\circ} \mathrm{E}, 50.23^{\circ} \mathrm{N}\right)$ for the time periods $03-31 \mathrm{January} 2004$ (a) and 12-31 August 2004 (b). Dashed and solid lines denote values from hourly rain gauge measurements and the disaggregated dataset, respectively. Horizontal black bars (drawn at a value of $1 \mathrm{~mm} / \mathrm{h}$ ) mark time periods where no values are available from the disaggregated dataset due to missing radar data.
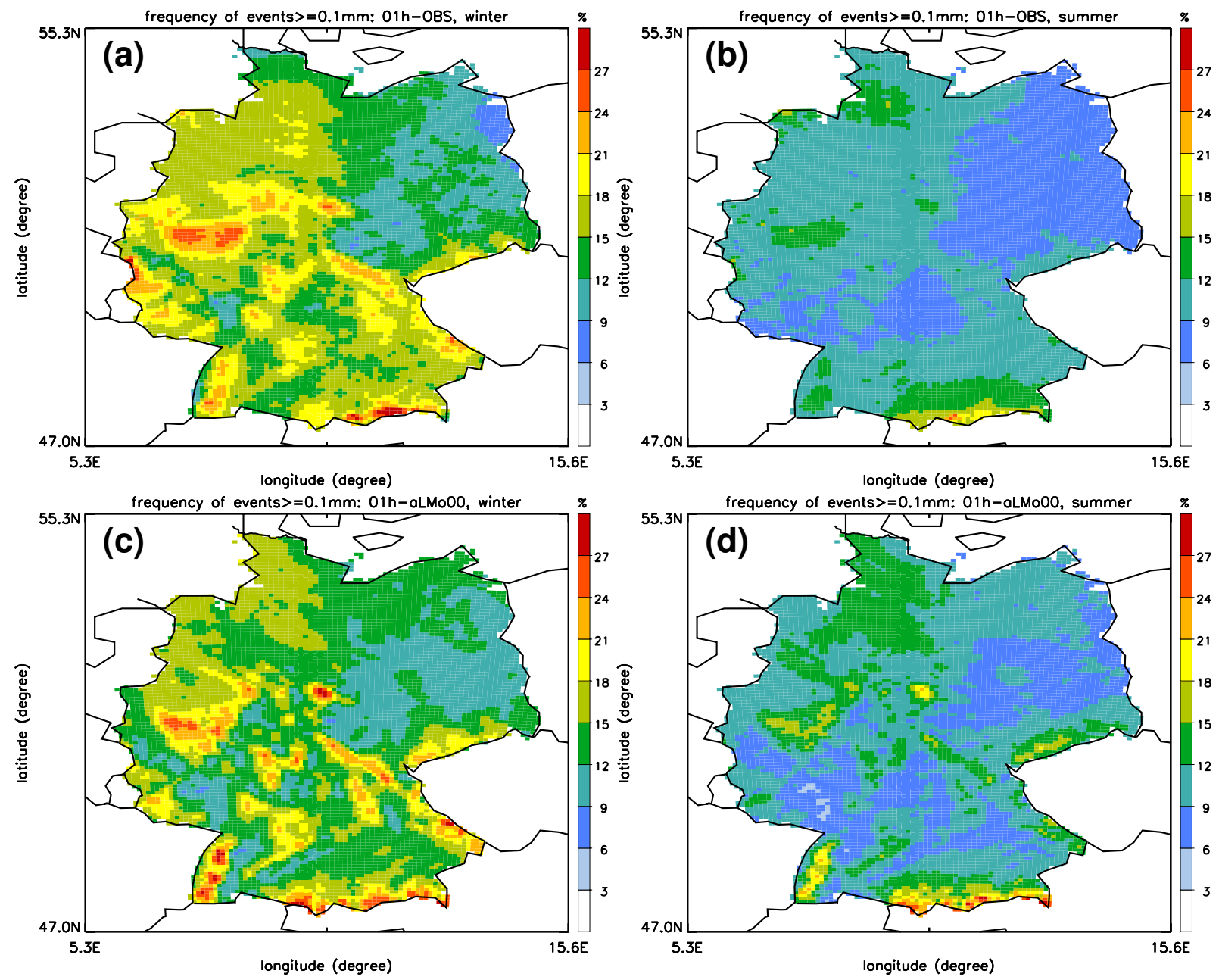

Figure 7: Geographical distribution of the frequency of hourly precipitation larger than $0.1 \mathrm{~mm} / \mathrm{h}$ (in \%) during the years 2001-2004, for the disaggregated dataset in winter (a) and summer (b); and for the COSMO-7 model in winter (c) and summer (d). 

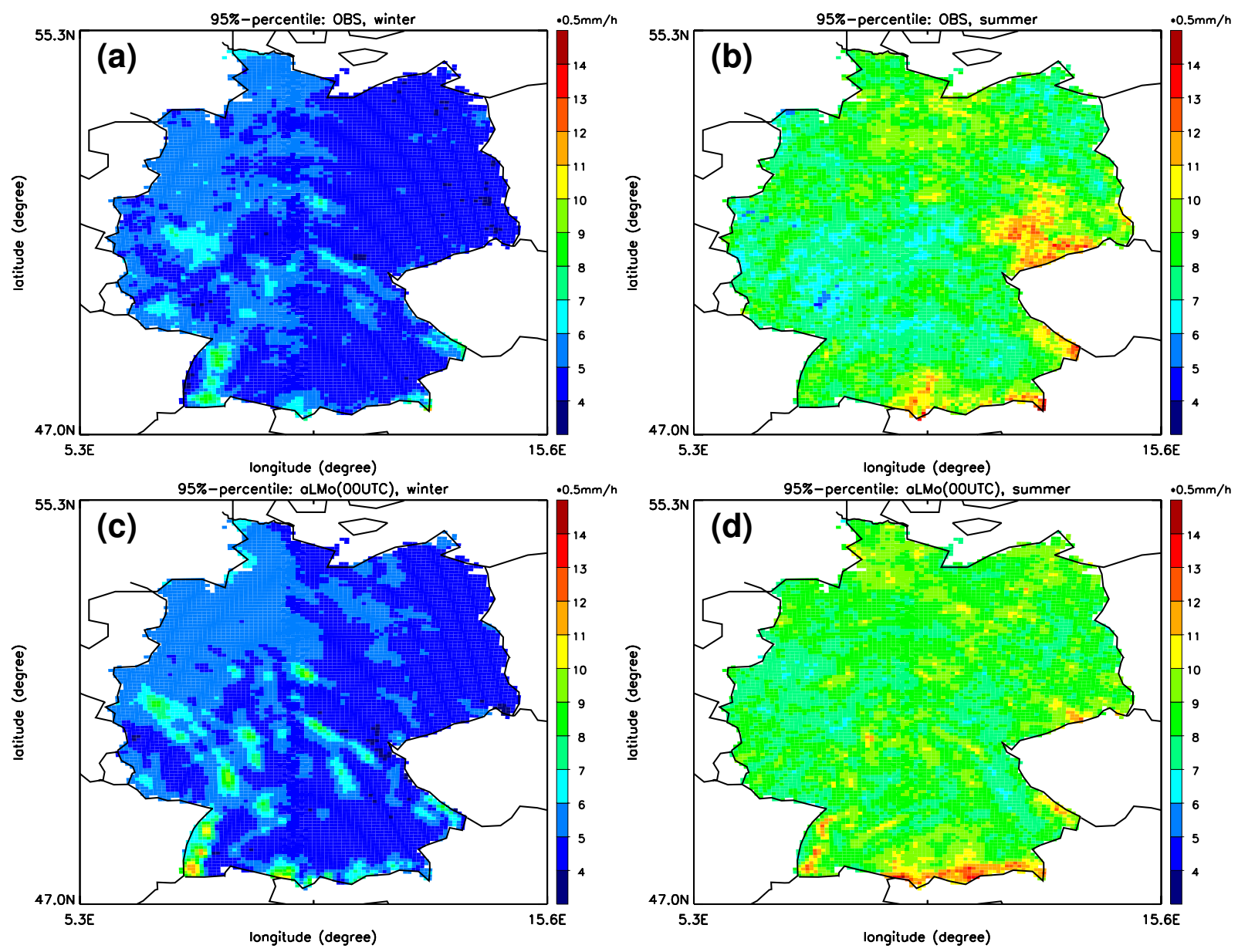

Figure 8: Geographical distribution of the $95 \%$ percentile of the frequency distribution of hourly precipitation at every grid point during the years 2001-2004, for the disaggregated dataset in winter (a) and summer (b); and for the COSMO-7 model in winter (c) and summer (d).

areas, i.e., in the same areas where precipitation is also most frequent (cf. Fig. 7a).

In summer (Fig. 8b), maxima are not obviously related to the topography, except for the south of Germany. Large values appear in the upper part of the Elbe catchment. They are no longer present when the analysis is repeated without the data for August 2002 (not shown), when extreme precipitation in the Erzgebirge led to a severe flooding of the river Elbe (e.g., JAMES et al., 2004). This indicates on the one hand that the disaggregated dataset captures the extreme character of this event, and on the other hand that the structure in the Elbe region apparent in Fig. 8a is only due to this particular event and not an indication of generally enhanced precipitation in this area.

\subsection{The diurnal cycle}

Another highly relevant aspect of the precipitation climatology during the warm season is the diurnal cycle, which occurs because of the importance of solar radiation for the triggering of convective storms. The hourly precipitation dataset offers the possibility to investigate the climatological diurnal cycle at every grid point, by averaging the values for a particular hour over all days. Two key parameters of the diurnal cycle, the hour when the maximum value occurs and the amplitude of the cycle (maximum minus minimum value during the day) are displayed in Fig. 9. Since no obvious diurnal cycle occurs for the other seasons, diagrams are only shown for summer. The value for the maximum hour is set to missing data if the amplitude at this particular grid point is low, that is if the maximum is less than $30 \%$ above the average daily rainfall at this grid point. Such a weak (or even absent) diurnal cycle occurs in Schleswig-Holstein in the very north of Germany, in parts of central Germany between the Westerwald and the Thüringer Wald and, surprisingly, at certain grid points in the Black Forest. In all other regions, the summertime diurnal cycle is pronounced with a maximum in the late evening (typically between 15-22 UTC, i.e. 17-24 local time, see Fig. 9a). The amplitude is largest in the NW part of Germany, in the mountainous regions along the Czech border, and in the Alpine Foreland (Fig. 9b).

Generally, the fields shown in Fig. 9 are relatively noisy. This is due to the short time series of four years 

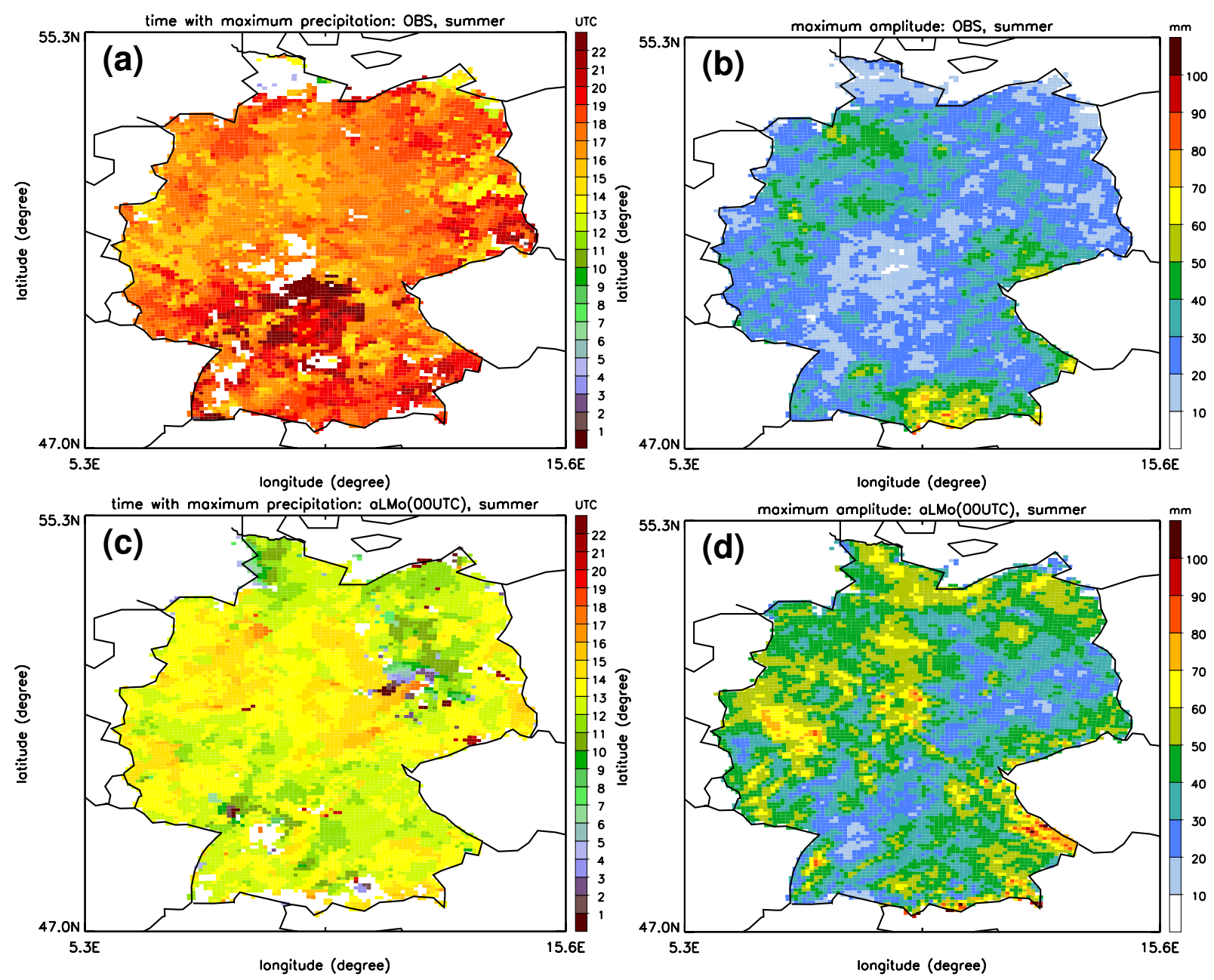

Figure 9: Geographical distribution of the hour with the maximum value (left panels) and amplitude (right panels) of the diurnal cycle during the summers 2001-2004, for the disaggregated dataset (a, b) and the COSMO-7 (c, d).

and the high spatial resolution of the analysis. However, a test with only three years of data indicated that the geographical patterns are fairly robust and that the future continuation of the time series will lead to less strong spatial gradients in the characteristics of the diurnal cycle.

\section{Comparison with QPFs from the COSMO-7 model}

In this section, the previously discussed climatological features of precipitation in Germany (i.e., the frequency of hourly precipitation, the 95th percentile of the frequency distribution, and the diurnal cycle) are analyzed for QPFs from the COSMO-7 model (cf. section 2.4) and compared with observations.

First, Fig. 7 reveals that the model captures the climatology of hourly precipitation frequency fairly well during both winter and summer. In winter, both the absolute numbers and the regional variability are reasonably well represented (compare Figs. 7a, c). Largest deviations occur near the Harz, in the Black Forest, and in parts of the
Alpine Foreland where the model overestimates the frequency. In contrast, in low elevation regions the frequencies are slightly underestimated by the model. Note for instance in the Black Forest area that precipitation frequency is overestimated by the model on the westward side and underestimated on the eastward side. This pronounced upwind/downwind pattern in the error of precipitation frequency is typical for the COSMO-7 model prior to changing from the diagnostic to the prognostic precipitation scheme (PAULAT, 2007). During summer, the same error pattern occurs (compare Figs. 7b, d), as well as slight overestimations of the precipitation frequency in some of the mountainous regions.

Secondly, also the 95th percentile of the frequency distribution (Fig. 8) is well captured by the model. It is remarkable that the general amplitude, its seasonal variation and many of the local extrema are in close agreement with observations. Notable differences occur throughout the year in the Black Forest (again with a pronounced upwind/downwind error pattern), and in summer with an overestimation in the Rhine-Main area and an underestimation in the upper Elbe catchment. 
The latter model error is due to underestimating the extreme intensity of the precipitation event that led to the Elbe flood in August 2002.

The final comparison, shown in Fig. 9, indicates a strongly erroneous behavior of the model in forecasting the diurnal cycle of precipitation during summer. In most regions, the model simulations started at 00 UTC predict the peak of the diurnal cycle between 11 and 15 UTC, i.e., typically 4-8 hours earlier than observed (compare Figs. 9a, c). Almost the same results emerge for the forecast started at 12 UTC (PAULAT, 2007). The errors in the peak hour are smallest in the NW part of the country and particularly large in eastern Germany; however, the reasons for this geographical variability are currently unclear. The model generally overestimates the amplitude of the diurnal cycle (Figs. 9b, d), in particular in northern Germany where the amplitude amounts to about $60 \mathrm{~mm}$ in the model compared to $20 \mathrm{~mm}$ in the observations. A similarly erroneous representation of the diurnal cycle of summertime precipitation has been reported also for other models and in other midlatitude regions (e.g., DAI et al., 1999; KAUFMANN et al., 2003), and it is hypothesized that the error is related to deficiencies in the parameterization of deep convection.

\section{Conclusions}

A disaggregation technique, gridded daily rain gauge measurements and hourly radar composites have been used in order to construct an hourly precipitation dataset for Germany on a grid with a horizontal resolution of $7 \mathrm{~km}$, so far for the years 2001-2004. The key characteristics of the technique are that at every grid point the daily total corresponds to the value of the gridded rain gauge analysis (which are considered as ground truth), and that the temporal variations during the day are determined by the radar. Problems associated with precipitation measurements by gauges and radar and their impact on the disaggregated dataset have been discussed. No disaggregation is possible at a certain grid point and during a certain day if the gridded gauge analysis indicates that precipitation has occurred at this point, but all radar composites are devoid of precipitation at this location. This occurs on $8 \%$ of all days during the considered four years and restricts the dataset to $92 \%$ of all possible days. Comparing the frequency distribution of the hourly-disaggregated dataset with the one of hourly station measurements reveals a close agreement (given the differing areal support of the two datasets).

The dataset has been used to investigate selected climatological characteristics of hourly precipitation in Germany. As expected, there are pronounced seasonal and regional differences in the frequency and in the 95th percentile of the hourly precipitation distribution. It appears that the following three geographical areas can be distinguished: (i) In the eastern part of Germany (except for the uppermost part of the Elbe catchment), hourly precipitation frequencies are lowest in all seasons, with fairly low seasonal variability. 95th percentile values are also low compared to other regions in Germany during winter, and particularly large during summer. However, the latter feature is influenced by the exceptional event that led to the Elbe flooding in summer 2002. The diurnal cycle is not very pronounced, with an amplitude of only 20 $\mathrm{mm}$ (except for larger values in the Erzgebirge).

(ii) Mountainous regions in the western part of Germany are characterized by maximum hourly precipitation frequencies during winter, strongly reduced frequencies during summer, and therefore amplified seasonal differences. During winter, also the 95th percentile values are largest in these areas. The intensity of the diurnal cycle differs and is largest in the Alpine Foreland.

(iii) The western Germany lowlands reveal intermediate seasonal variations and in the Rhine-Main area very low values of hourly precipitation frequency and the 95th percentile during both summer and winter. The amplitude of the diurnal cycle is geographically highly variable. In the future, it will be interesting to analyze the dynamical factors that determine these regional differences. For instance, it is an open question whether the eastern part of Germany is more frequently affected by relatively dry continental air masses (compared to western Germany) or whether the relative dryness is due to rain out in saturated air masses that traverse the country from west to east. Also, it could be rewarding to investigate the diurnal cycle in both the observational and simulated datasets for different synopticscale weather categories (TwARDOSZ, 2007). Data sets of hourly precipitation are also very useful for investigating the dynamical processes leading to precipitation events (CLAUSSNITZER et al., 2008).

In a final part of the study, the key aspects of the hourly precipitation distribution have been investigated as simulated by a mesoscale operational numerical weather prediction model with parameterized deep convection. While the frequency of hourly precipitation and the 95th percentile values are well captured by the model, significant deficiencies occur for the diurnal cycle. Throughout Germany, the model produces a too strong diurnal cycle that peaks several hours too early (shortly after midday instead of in the early evening). This problem is common to several weather prediction models in midlatitudes, and it will be interesting to investigate the performance of convection-permitting model versions (e.g., the COSMO-DE with a horizontal resolution of $2.8 \mathrm{~km}$, operated by the German Weather Service since April 2007). First results from the WRF model in the United States (CLARK et al., 2007) indicate that the convectionpermitting version represents the diurnal cycle better, at least during the second day of the simulations. The MAP D-PHASE project in summer and autumn 2007, which delivered QPFs from a multitude of models with differ- 
ent resolutions and physical parameterizations, yields a comprehensive dataset to further analyze differences in the models' QPF performance in Central Europe, and to improve our understanding of the reasons behind the identified model deficiencies.

During the next years, the disaggregated dataset of hourly precipitation in Germany on the $7 \mathrm{~km}$-grid will be continuously extended and used for standard and objectbased verification of QPFs in major German river catchments (e.g., with the SAL technique, WERNLI et al., in press). For research applications, the dataset is available from the authors in NetCDF format.

\section{Acknowledgments}

The authors are grateful for the funding of the present study as part of the Priority Programme SPP 1167 of the German Science Foundation (DFG). We are also grateful to the DWD for providing access to the rain gauge and radar data, and to MeteoSwiss for the COSMO-7 forecasts.

\section{References}

BATTAN, L.J., 1973: Radar observation of the atmosphere. The University of Chicago Press, $324 \mathrm{pp}$.

BEHRENDT, J. 1992. Dokumentation ROUTKLI: Beschriebung der Prüfkriterien im Programmsystem QUALKO. - To be obtained from Deutscher Wetterdienst, Abteilung Klimatologie, Offenbach a.M., Germany, 12 pp.

Clark, A.J., W.A. Gallus JR., T.-C. Chen, 2007: Comparison of the diurnal precipitation cycle in convectionresolving and non-convection-resolving mesoscale models. - Mon. Wea. Rev. 145, 3456-3473.

Claussnitzer, A., P. Nevir, I. LAnger, E. Reimer, U. CUBASCH, 2008: Scale-Dependent analyses of precipitation forecasts and cloud properties using the Dynamic State Index. - Meteorol. Z. 17, 813-825.

DAi, A., F. Giorgi, K.E. Trenberth, 1999: Observed and model-simulated diurnal cycles of precipitation over the contiguous United States. - J. Geophys. Res. 104, 63776402.

DeGaetano, A.T., D.S. Wilks, 2008: Radar-guided interpolation of climatological precipitation data. - Int. J. Climatol., published online, DOI:10.1002/joc.1714, 12 pp.

Ebert, E.E., U. DAmrath, W. Wergen, M.E. BALDWIN, 2003: The WGNE assessment of short-term quantiatitve precipitation forecasts. - Bull. Amer. Meteor. Soc. 84, 481-492.

EKHART, E., 1948: Die Niederschlagsverteilung in den Alpen nach dem Anomalienprinzip. - Geogr. Ann. 30, 728-739.

FREI, C., C. SCHÄR, 1998: A precipitation climatology of the Alps from high-resolution rain-gauge observations. Int. J. Climatol. 18, 873-900.

Frei, C., J.H. Christensen, M. DÉQué, D. Jacob, R.G. JONES, P.L. VIDALE, 2003: Daily precipitation statistics in regional climate models: evaluation and intercomparison for the European Alps. - J. Geophys. Res. 108, 4124, DOI:10.1029/2002JD002287.
Frei, C., U. Germann, S. Fukutome, M. Liniger, in print: Möglichkeiten und Grenzen der Niederschlagsanalysen zum Hochwasser 2005. - In: G. R. BEZzOLA, C. HEGG (Eds.), Ereignisanalyse Hochwasser 2005, Teil 2.

FRITSCH, J.M., R.E. CARBONE, 2004: Improving quantitative precipitation forecasts in the warm season. - Bull. Amer. Meteor. Soc. 85, 955-965.

Gekat, F., P. Meischner, K. Friedrich, M. Hagen, J. Koistinen, D.B. Michelson, A. Huuskonen, 2003: The state of weather radar operations, networks and products. - In: MEISCHNER, P. (Ed.): Weather Radar: Principles and Advanced Applications. Physics of Earth and Space Environments, Springer, Berlin, 1-51.

Germann, U., G. Galli, M. Boscacci, M. Bolliger, 2006: Radar precipitation measurement in a mountainous region. - Quart. J. Roy. Meteor. Soc. 132, 1669-1692.

GJertsen, U., M. SAleK, D.B. Michelson, 2004: Gauge adjustment of radar-based precipitation estimates in Europe. - Proc. European Conf. on Radar Meteorology 2004, Visby, Sweden, 7-11.

HABERLANDT, U., 2007: Geostatistical interpolation of hourly precipitation from rain gauges and radar for a largescale extreme rainfall event. - J. Hydrol. 332, 144-157.

Hagen, M., C. Frei, C. SCHÄR, 2003: Temporal disaggregation of rain-gauge analyses using radar. - Presentation at the International Conference on Alpine Meteorology and MAP-meeting, Brig, Switzerland.

James, P., A. Stohl, N. Spichtinger, S. ECKhardt, C. FORSTER, 2004: Climatological aspects of the extreme European rainfall of August 2002 and a trajectory method for estimating the associated evaporative source regions. NHESS 4, 733-746.

Kaufmann, P., F. Schubiger, P. Binder, 2003: Precipitation forecasting by a mesoscale numerical weather prediciton (NWP) model: eight years of experience. HESS 7, 812-832.

MÜLler-Westermeier, G., 1995: Numerisches Verfahren zur Erstellung klimatologischer Karten. - Berichte des Deutschen Wetterdienstes 193, 17 pp.

NEFF, E.L., 1977: How much rain does a rain gauge gauge? - J. Hydrol. 35, 213-220.

New, M., M. Hulme, P. Jones, 2000: Representing twentieth-century space-time climate variability. Part II: Development of 1901-96 monthly grids of terrestrial surface climate. - J. Climate 13, 2217-2238.

Osborn, T.J., M. Hulme, 1997: Development of a relationship between station and grid-box rainday frequencies for climate model evaluation. - J. Climate 10, 1885-1908.

PAUlAT, M., 2007: Verifikation der Niederschlagsvorhersage für Deutschland von 2001-2004. - PhD thesis University of Mainz, (available from the author), $155 \mathrm{pp}$.

PECK, E.L., M.J. Brown, 1962: An approach to the development of isohytal maps for mountainous areas. - J. Geophys. Res. 67, 681-694.

RICHTER, D., 1995: Ergebnisse methodischer Untersuchungen zur Korrektur des systematischen Messfehlers des Hellmann-Niederschlagsmessers. - Berichte des Deutschen Wetterdienstes 194, 93 pp.

Ross A, A., P. NuRmi, E. EBERT, in preparation: Overview of methods for the verification of quantitative precipitation forecasts. - Book chapter.

Rudolf, B., H. Hauschild, M. Reiss, U. SCHneider, 1992: Die Berechnung der Gebietsniederschläge im $2.5^{\circ}$ Raster. - Meteorol. Z. 1, 32-50. 
SEO D.-J., 1998: Real-time estimates of rainfall fields using radar rainfall and rain gauge data. - J. Hydrol. 208, 37-52.

SeO D.-J., W.F. Krajewski, D.S. Bowles, 1990: Stochastic interpolation of rainfall data from rain gages and radar using Cokriging 1. Design of experiments. - Water Resourc. Res. 26, 469-477.

SHEPARD, D.S., 1984: Computer mapping: the SYMAP interpolation algorithm. - In: G. L. GAILE, C.J. WILLMOT (Eds.), Spatial statistics and models, Dordrecht, 133-145.

Steppeler, J., G. Doms, U. Schättler, H.W. Bitzer, A. Gassmann, U. DAMrath, G. Gregoric, 2003: Meso-gamma scale forecasts using the nonhydrostatic model LM. - Meteor. Atmos. Phys. 82, 75-96.

Todini, E., 2001: A Bayesian technique for conditioning radar precipitation estimates to rain-gauge measurements. - HESS 5, 187-199.

Trenberth, K.E., 1999: Conceptual framework for changes of extremes of the hydrological cycle with climate change. - Climatic Change 42, 327-339.
TwARDOSZ, R., 2007: Diurnal variation of precipitation frequency in the warm half of the year according to circulation types in Krakow, South Poland. - Theor. Appl. Climatol. 89, 229-238.

Wernli, H., M. Paulat, M. Hagen, C. Frei, in press: $\mathrm{SAL}$ - a novel quality measure for the verification of quantitative precipitation forecasts. - Mon. Wea. Rev.

WidmanN, M., C.S. Bretherton, 2000: Validation of mesoscale precipitation in the NCEP reanalysis using a new gridcell dataset for the northwestern United States. J. Climate 13, 1936-1950.

Wüest, M., C. Frei, A. Altenhoff, M. Hagen, M. LITSCHI, C. SCHÄR, submitted: A gridded hourly precipitation dataset for Switzerland using rain-gauge analysis and radar-based disaggregation. - Int. J. Climatol.

Yang D. Q., E. ElomaA, A. TuOminen, A. Aaltonen, B. Goodison, T. Gunther, V. Golubev, B. Sevruk, H. MAdSEN, J. MilKoviC, 1999: Wind-induced precipitation undercatch of the Hellmann gauges. - Nordic Hydrol. 30, 57-80. 